\title{
Diversity, Pathogenicity, and Fungicide Sensitivity of Colletotrichum Species Associated with Apple Anthracnose in South Korea
}

\author{
Chi Hyun Kim, Oliul Hassan, and Taehyun Chang ${ }^{\dagger}$ \\ Department of Ecology and Environmental System, College of Ecology and Environmental Sciences, Kyungpook National \\ University, Sangju, Gyeongbuk 37224, Republic of Korea
}

\begin{abstract}
Apple fruits with anthracnose symptoms were collected from commercial apple orchards in different regions of the Republic of Korea, and isolations were made on potato dextrose agar to isolate the causal agents. The fungal isolates were identified based on their morphological characteristics, growth rates, and multigene sequences. Nine isolates were identified via phylogenetic analysis: three Colletotrichum fructicola, two $C$. fioriniae, one C. gloeosporioides sensu stricto (s.s.), two C. nymphaeae, and one

study also reidentified six Colletotrichum isolates responsible for apple anthracnose, which were deposited in the Korean Agricultural Culture Collection. Among the six isolates, three were identified as $C$. siamense (deposited as $C$. gloeosporioides s.s.), and three were $C$. nymphaeae (deposited as C. acutatum s.s.). All the Colletotrichum species identified in this study were highly sensitive to tebuconazole in terms of inhibition of mycelial growth $\left(\mathrm{EC}_{50}\right.$ value of 0.12 to $\left.2.1 \mu \mathrm{g} / \mathrm{ml}\right)$.
\end{abstract} $C$. siamense isolates. The pathogenicity of the Colletotrichum isolates was tested using detached apple fruits under laboratory conditions. This
Keywords: Colletotrichum species, anthracnose, fungicide sensitivity
In addition to persimmon, pear, grape, and peach, apple is one of the major fruit crops commercially cultivated in South Korea (KREI 2018). On average, South Korea produces around 540,000 metric tons of apples a year. 'Tsugaru', 'Hongro', 'Yangkwang', 'Gamhong', and 'Fuji' are the most common apple cultivars grown in South Korea, with Fuji accounting for $70 \%$ of the total apple cultivation area (KREI 2018). Most apple growers choose Fuji because it has certain advantages over other cultivars, such as a longer storage life, and Korean consumers also prefer Fuji apples for their juicy flavor and crisp texture (Choi and Hinkle 2017).

The weather conditions and diseases caused by bacteria, viruses, and fungi are the main challenges for apple growers in South Korea. For example, in 2018, many orchards in Sangju experienced sunburn and smaller apple sizes due to long spells of high temperatures, which are known to reduce the size of apples (Basannagari and Kala 2013). Anthracnose, scab, apple blotch, white rot, Alternaria leaf spot, and bacterial shoot blight are the major apple diseases in South Korea (Cheon and Jeon 2015; Kim et al. 2018; KSPP 2009; Lee at al. 2017; Park et al. 2018). Among these diseases, anthracnose (also known as bitter rot) is an annual threat to the apple industry. Apple anthracnose is characterized by sunken lesions on apples and is responsible for their decay and reduction in quality. It is not possible to sell fruit affected by this disease on the market; thus, apple growers face severe economic losses if they cannot control it.

The fungus genus Colletotrichum consists of about 189 species, including 11 species complexes (Baroncelli et al. 2017). This pathogen is distributed across the world and is able to infect a wide range of hosts (Faedda et al. 2011; Fu et al. 2019; Guarnaccia et al. 2019). In particular, it is associated with apple anthracnose (Kim et al. 2018), with Colletotrichum fructicola and C. siamense reported to be the causal agents of apple anthracnose in South Korea (Kim et al. 2018; Park et al. 2018). Recently, C. siamense, C. fructicola, C. fioriniae, and C. nymphaeae have been reported

${ }^{\dagger}$ Corresponding author: T. Chang; thchang@knu.ac.kr

The author(s) declare no conflict of interest.

Accepted for publication 9 May 2020.

(C) 2020 The American Phytopathological Society in Malus domestica in South Korea by Oo et al. (2018). In addition, a complex of Colletotrichum species such as $C$. siamense, $C$. theobromicola, C. fructicola, C. fioriniae, and C. nymphaeae has been reported to cause anthracnose in Kentucky orchards in the United States (Munir et al. 2016). C. gloeosporioides sensu stricto (s.s.), previously reported from apple in South Korea, was not identified by the study of Oo et al. (2018). Therefore, further research is needed on the etiology and epidemiology of apple anthracnose in South Korea. Oo et al. (2018) identified Colletotrichum species based on their morphological characteristics and nucleotide sequence data of internal transcribed spacer (ITS) regions and glyceraldehyde-3-phosphate dehydrogenase (GAPDH). Due to intraspecies overlap in terms of morphological characteristics, it has been difficult to distinguish closely related Colletotrichum species. ITS and GAPDH are not enough for distinguishing Colletotrichum species (Weir et al. 2012). Silva et al. (2012) suggested using the ApMat gene for the identification of $C$. siamense. Multilocus phylogenetic analysis has become a popular tool to delineate Colletotrichum species within a species complex (Damm et al. 2012; Weir et al. 2012). By applying this approach, several new species have been recorded recently. C. bannanense, $C$. australisinense, and $C$. cairnsense have been recorded within the $C$. acutatum species complex, and $C$. ledongense has been identified in the $C$. gloeosporioides species complex (De Silva et al. 2017; Liu et al. 2018). Several articles focused on the diversity of Colletotrichum species associated to anthracnose of a single crop (Fu et al. 2019; Hassan et al. 2018, 2019a; Lubbe et al. 2004). The continuous recognition of novel species within particular species complexes, and several species being associated to a single crop in particular, make it more important for systematic studies to be conducted on the Colletotrichum species associated with apple anthracnose. In particular, the identification of Colletotrichum species is essential for the effective control of this disease. To enhance the effective management of anthracnose, determination of fungicide sensitivity of Colletotrichum spp. isolates is necessary. Sensitivity of various Colletotrichum spp. is not the same against a particular fungicide (Chen et al. 2016).

The objectives of this study were (i) to investigate the diversity of Colletotrichum species associated with apple anthracnose in Korea by studying their morphological characteristics and conducting multilocus phylogenic analysis, (ii) to investigate the pathogenicity of different Colletotrichum species, and (iii) to examine the sensitivity of different Colletotrichum species isolated from apple to fungicides. 


\section{Materials and Methods}

Collection of fungal isolates. In 2018 and 2019, affected apples exhibiting typical anthracnose symptoms were collected from commercial Fuji, Tsugaru, and Hongro apple orchards in the Sangju, Gimcheon, and Gumi regions of South Korea. Fungal isolates were obtained from the diseased fruit using the tissue-isolation method. For this, the collected apples were washed thoroughly with tap water, and small pieces of the skin and pulp were cut from the outer margin of the lesions. To sterilize the surface, the skin and pulp were dipped in $0.1 \% \mathrm{NaOCl}$ solution for $1 \mathrm{~min}$, rinsed with sterilized distilled water three times, and finally air dried in a laminar flow hood. Disinfested fruit tissue was placed on a Petri plate of water agar and incubated at $25^{\circ} \mathrm{C}$ in the dark. After 2 days of incubation, the hyphal tips emerging from the skin and pulp were transferred to plates of potato dextrose agar (PDA, Difco, Becton Dickinson) and incubated in the dark at $25^{\circ} \mathrm{C}$. Fungal isolates were preserved in $20 \%$ glycerol at $-70^{\circ} \mathrm{C}$ in the plant tissue culture laboratory at Kyungpook National University for further use.

In addition, six Colletotrichum isolates responsible for apple anthracnose were taken from the Korean Agricultural Culture Collection (KACC), South Korea. Three of these isolates from the KACC have previously been identified as $C$. gloeosporioides s.s., and the other three as $C$. acutatum s.s. based on their ITS sequences and morphological characteristics.

DNA extraction, target gene amplification, and sequencing. The mycelium from a 4-day-old culture of each isolate was used for genomic DNA extraction. Around $10 \mathrm{~g}$ of the mycelium from each culture was lyophilized first, and the genomic DNA was then isolated using a HiGene Genomic DNA Prep Kit (Biofact, Yuseong-Gu, Daejeon, Korea) following the instructions of the manufacturer. Variable regions of the genomic DNA were amplified and sequenced, including ITS and a partial sequence of beta-tubulin (TUB2), calmodulin (CAL), GAPDH, actin (ACT), chitin synthase 1 (CHS-1), and the Apn2-Mat1-2 intergenic spacer and the partial mating type (Mat1-2) gene (ApMat). Six loci (ITS, TUB2, GAPDH, CHS-1, CAL, and ApMat) and four loci (ITS, TUB2, GAPDH, and CHS-1) were selected for the $C$. gloeosporioides sensu lato (s.l.). and C. acutatum s.l. isolates, respectively. The primer sets ITS1 + ITS4 (White et al. 1990), Bt2a + Bt2b (Glass and Donaldson 1995), GDF + GDR (Templeton et al. 1992), CHS-79F + CHS-345R (Carbone and Kohn 1999), CL1C + CL2C (Weir et al. 2012), and AM-F and AM-R (Silva et al. 2012) were used for the amplification and sequencing of ITS, TUB2, GAPDH, CHS-1, CAL, and ApMat respectively (Table 1). The process and conditions for polymerase chain reaction (PCR) amplification were adopted from Hassan et al. (2018), with the purification and sequencing of the PCR products performed commercially at Macrogen (Seoul, Korea). The resulting sequences were deposited in NCBI GenBank; the accession numbers are listed in Table 2.

Phylogenetic analysis. The gene sequences of each ex-type Colletotrichum sp. used in the phylogenetic studies by Weir et al. (2012) and Damm et al. (2012) were downloaded from GenBank. Each gene sequence of the isolates from the present study and those from the extype Colletotrichum spp. were aligned using the MUSCLE multiple sequence alignment program in MEGA version 6.0 (Tamura et al. 2013), and all gaps were treated as missing data. The multiple sequence alignment for each gene was concatenated using Mesquite version 2.75 (Maddison and Maddison 2011). The concatenated sequences of different gene combinations were used to construct maximum likelihood and maximum parsimony phylogenetic trees using

Table 1. List of primers used for PCR amplification and sequencing

\begin{tabular}{llllcl}
\hline Gene & Primer name & Direction & \multicolumn{1}{c}{ Sequence $\left(\mathbf{5}^{\prime} \mathbf{- \mathbf { 3 } ^ { \prime } )}\right.$} & Annealing temperature $\left({ }^{\circ} \mathbf{C}\right)$ & References \\
\hline GAPDH & GDF & Forward & GCCGTCAACGACCCCTTCATTGA & 60 & Templeton et al. (1992) \\
& GDR & Reverse & GGGTGGAGTCGTACTTGAGCATGT & 60 & Templeton et al. (1992) \\
ITS & ITS1 & Forward & TCCGTAGGTGAACCTGCGG & 55 & White et al. (1990) \\
& ITS4 & Reverse & TCCTCCGCTTATTGATATGC & 55 & White et al. (1990) \\
CAL & CL1C & Forward & GAATTCAAGGAGGCCTTCTC & 59 & Weir et al. (2012) \\
& CL2C & Reverse & CTTCTGCATCATGAGCTGGAC & 59 & Weir et al. (2012) \\
ApMat & AM-F & Forward & TCATTCTACGTATGTGCCCG & 62 & Silva et al. (2012) \\
& AM-R & Reverse & CCAGAAATACACCGAACTTGC & 62 & Silva et al. (2012) \\
TUB2 & Bt2a & Forward & GGTAACCAAATCGGTGCTGCTTTC & 55 & Glass and Donaldson (1995) \\
& Bt2b & Reverse & ACCCTCAGTGTAGTGACCCTTGGC & 55 & Glass and Donaldson (1995) \\
CHS-1 & CHS-79F & Forward & TGGGGCAAGGATGCTTGGAAGAAG & 58 & Carbone and Kohn (1999) \\
& CHS-345R & Reverse & TGGAAGAACCATCTGTGAGAGTTG & 58 & Carbone and Kohn (1999) \\
\hline
\end{tabular}

Table 2. GenBank accession numbers for the identified Colletotrichum isolates

\begin{tabular}{|c|c|c|c|c|c|c|c|}
\hline \multirow[b]{2}{*}{ Species } & \multirow[b]{2}{*}{ Isolate } & \multicolumn{6}{|c|}{ GenBank accession number } \\
\hline & & ITS & GAPDH & TUB2 & CHS-1 & CAL & ApMat \\
\hline C. gloeosporioides & ICKa85 & LC499040 & LC499057 & LC499048 & LC499071 & LC499085 & . \\
\hline \multirow[t]{4}{*}{ C. siamense } & ICKa38 & LC499039 & LC499056 & LC499047 & LC499070 & LC499084 & LC499089 \\
\hline & KACC 42494 & KA002861 & LC499058 & KA002890 & LC499072 & LC499086 & LC499090 \\
\hline & KACC 42497 & KA002863 & LC499059 & KA002888 & LC499074 & LC499087 & LC499091 \\
\hline & KACC 42498 & KA002864 & L90C4960 & KA002887 & LC499075 & LC499088 & LC499092 \\
\hline \multirow[t]{3}{*}{ C. fructicola } & ICKa13 & LC499038 & LC499055 & LC499046 & LC499069 & LC499083 & $\ldots$ \\
\hline & ICKa14 & LC499037 & LC499045 & LC499054 & LC499068 & LC499082 & $\ldots$ \\
\hline & ICKa15 & LC381301 & LC499053 & LC381302 & LC381304 & $\ldots$ & $\ldots$ \\
\hline \multirow[t]{5}{*}{ C. nymphaeae } & ICKS18 & LC499041 & LC499061 & LC499049 & LC499075 & $\ldots$ & $\ldots$ \\
\hline & ICKS19 & LC499042 & LC499062 & LC499050 & LC499076 & $\ldots$ & $\ldots$ \\
\hline & KACC42403 & KA002860 & LC499065 & KA002891 & LC499079 & $\ldots$ & $\ldots$ \\
\hline & KACC40847 & KA002638 & LC499066 & KA002682 & LC499080 & $\ldots$ & $\ldots$ \\
\hline & KACC40848 & KA002639 & LC499067 & KA002683 & LC499081 & $\ldots$ & $\ldots$ \\
\hline \multirow[t]{2}{*}{ C. fioriniae } & ICKS30 & LC499043 & LC499063 & LC499051 & LC499077 & $\ldots$ & $\ldots$ \\
\hline & ICKS31 & LC499044 & LC499064 & LC499052 & LC499078 & $\ldots$ & $\ldots$ \\
\hline
\end{tabular}


MEGA version 6.0 software (Tamura et al. 2013). A Bayesian inference consensus tree based on a $50 \%$ majority rule was constructed using MrBayes version 3.2 (Ronquist et al. 2012). A Markov chain Monte Carlo sampler was employed to sample trees and posterior probabilities of model parameters. Four Markov chains were run with the full data set for $1 \times 10^{6}$ generations, with a sampling frequency of once every 100 generations. The first $25 \%$ of the burn-in generations were discarded. The resulting $50 \%$ majority rule consensus tree was visualized using FigTree version 1.3.1 (Rambaut and Drummond 2009).

Morphological analysis. The colony color, mycelial growth rate, and morphology of each isolate (except the KACC isolates) on PDA were recorded over the course of 7 days of incubation at $25^{\circ} \mathrm{C}$ in the dark. The effects of temperature and the culture media on the mycelial growth of the isolates was also investigated. To assess the effect of temperature, a 5-mm mycelial plug from the 7-day-old culture of each isolate was placed on fresh PDA plates and incubated in the dark at $15,20,25$, and $30^{\circ} \mathrm{C}$. Similarly, a 5-mm mycelial plug from the 7day-old culture of each isolate was placed on PDA, oatmeal agar (OA), malt agar (MA), and V8 and incubated at $25^{\circ} \mathrm{C}$ in the dark. Both experiments consisted of three replications and were repeated twice. The colony diameter was measured after 7 days of incubation. The shape and size of the conidia and appressoria were determined by mounting the conidial mass from each culture on a glass slide in distilled water. The sizes of 50 random conidia from each isolate were measured using an Olympus BX43 microscope with a magnification of 400x. To produce appressoria, a mounted conidial slide for each isolate was placed in a plastic box containing moistened tissue and incubated at $25^{\circ} \mathrm{C}$ in the dark. Appressoria were produced after 2 days of incubation. The sizes of 30 random appressoria from each isolate were measured in the same manner as for the conidia.

Pathogenicity testing. One representative isolate was chosen for pathogenicity testing from each recognized Colletotrichum sp. Healthy and unwounded mature apple fruits were collected from a commercial orchard, washed with tap water, and disinfected in $1 \%$ sodium hypochlorite for $3 \mathrm{~min}$. The disinfected apples were washed with sterilized water three times, dried in a laminar flow hood, and then placed on a sterilized plastic saucer in a sterilized plastic box with wet tissue. A conidial suspension of Colletotrichum spp. $\left(10^{6}\right.$ conidia/ml) was used to inoculate the disinfected fruit. This conidial suspension was prepared from a 7-day-old culture of each isolate on PDA. In each culture, 5 to $10 \mathrm{ml}$ of sterile distilled water was added, and the mycelia were scraped from the plates and filtered through two layers of Kimtech wipes. To inoculate the apples, both wounding and nonwounding techniques were adopted. In the former, the epidermis of the apples was wounded with a sterile syringe needle, and a drop of $10 \mu \mathrm{l}$ of the conidial suspension was placed over the wound (three wounds per fruit); in the latter, the conidial suspension was sprayed over the apples. Sterilized distilled water was used to treat the control fruit. The plastic boxes were sealed and maintained in an incubator at $25^{\circ} \mathrm{C}$. After 5 days of incubation, the lesion size (diameter) and disease incidence in terms of percentage of lesion development per isolate were measured. For both inoculation methods, five apples were tested for each isolate, and the experiment was repeated twice.

Determination of sensitivity of Colletotrichum isolates to fungicides. Four fungicides, including thiophanate-methyl, tebuconazole, azoxystrobin, and carbendazim, were used for Colletotrichum species sensitivity analysis. For 25 different Colletotrichum species, $50 \%$ effective concentration $\left(\mathrm{EC}_{50}\right)$ values were determined using mycelial growth assays. Less than 1 week old and vigorously growing culture of each isolate on PDA was used for the experiment. Plugs of $5 \mathrm{~mm}$ in diameter, containing actively growing mycelium, were transferred to PDA amended with fungicides, and in addition nonamended PDA was used as a control. PDA was amended with the active ingredient of thiophanate-methyl at $0.05,0.1,0.5,1$, and $2 \mu \mathrm{g} / \mathrm{ml}$; tebuconazole at $0.0083,0.016,0.083,0.83$, and $2 \mu \mathrm{g} / \mathrm{ml}$; azoxystrobin at $0.05,0.1,0.5,1$, and $2 \mu \mathrm{g} / \mathrm{ml}$; and carbendazim at $0.05,0.1,0.5,1$, and $2 \mu \mathrm{g} / \mathrm{ml}$. All fungicides were added to PDA after autoclaving. A plug was placed in the center of the PDA plate. Petri plates were sealed with Parafilm and incubated at $25^{\circ} \mathrm{C}$ in the dark. Radial mycelium growth was measured after 3 days of incubation. The diameter of each colony was measured by subtracting the 5$\mathrm{mm}$ plug from two perpendicular diameters and then averaging them. The relative mycelial growth percentage $(\mathrm{RMG} \%)$ for each isolate at each test concentration was calculated by comparing the growth on amended media (GOA) compared with the growth on the nonamended control $(\mathrm{GOC})$ as follows: $\mathrm{RMG} \%=(\mathrm{GOA} / \mathrm{GOC}) \times 100$. The percentage inhibition of mycelium growth for each isolate at

Table 3. Preliminary identification of Colletotrichum isolates based on a BLASTn search using ITS sequences and conidial morphology

\begin{tabular}{|c|c|c|c|}
\hline Isolates & $\begin{array}{l}\text { Closest Colletotrichum spp. in GenBank } \\
\text { based on resulting ITS sequences }\end{array}$ & Conidia & Remark \\
\hline ICKS1 & C. gloeosporioides (similarity: $100 \%$ ) & Cylindrical & C. gloeosporioides s.1. \\
\hline ICKS5 & C. gloeosporioides (similarity: 99\%) & Cylindrical & C. gloeosporioides s.l. \\
\hline ICKS17 & C. siamense (similarity: $99.2 \%$ ) & Cylindrical & C. gloeosporioides s.1. \\
\hline ICKa13 & C. fructicola (similarity: $100 \%$ ) & Cylindrical & C. gloeosporioides s.1. \\
\hline ICKa14 & C. fructicola (similarity: $100 \%$ ) & Cylindrical & C. gloeosporioides s.1. \\
\hline ICKa15 & C. fructicola (similarity: $99.9 \%$ ) & Cylindrical & C. gloeosporioides s.1. \\
\hline ICKS18 & C. acutatum (similarity: 99\%) & Fusiform & C. acutatum s.l. \\
\hline ICKS19 & C. acutatum (similarity: 99\%) & Fusiform & C. acutatum s.l. \\
\hline ICKS20 & C. acutatum (similarity: $100 \%$ ) & Fusiform & C. acutatum s.l. \\
\hline ICK21 & C. acutatum (similarity: 99\%) & Fusiform & C. acutatum s.l. \\
\hline ICKS24 & C. gloeosporioides (similarity: 99\%) & Cylindrical & C. gloeosporioides s.l. \\
\hline ICKa25 & C. fructicola (similarity: $99.9 \%$ ) & Cylindrical & C. gloeosporioides s.1. \\
\hline ICKa28 & C. fructicola (similarity: $99.27 \%$ ) & Cylindrical & C. gloeosporioides s.1. \\
\hline ICKS30 & C. acutatum (similarity: $99.8 \%$ ) & Fusiform & C. acutatum s.1. \\
\hline ICKS31 & C. acutatum (similarity: $100 \%$ ) & Fusiform & C. acutatum s.l. \\
\hline ICKa38 & C. siamense (similarity: $99.2 \%$ ) & Cylindrical & C. gloeosporioides s.1. \\
\hline ICKS52 & C. fructicola (similarity: 99.9\%) & Cylindrical & C. gloeosporioides s.l. \\
\hline ICKS54 & C. fructicola (similarity: $99.9 \%$ ) & Cylindrical & C. gloeosporioides s.l. \\
\hline ICKS55 & C. acutatum (similarity: 99\%) & Fusiform & C. acutatum s.l. \\
\hline ICKS57 & C. fructicola (similarity: $99.9 \%$ ) & Cylindrical & C. gloeosporioides s.1. \\
\hline ICKS61 & C. acutatum (similarity: $99.75 \%$ ) & Fusiform & C. acutatum s.1. \\
\hline ICKS63 & C. acutatum (similarity: $99.45 \%$ ) & Fusiform & C. acutatum s.l. \\
\hline ICKS71 & C. acutatum (similarity: $99.17 \%$ ) & Fusiform & C. acutatum s.l. \\
\hline ICKS85 & C. gloeosporioides (similarity: $99.9 \%$ ) & Cylindrical & C. gloeosporioides s.l. \\
\hline ICKS92 & C. acutatum (similarity: $99.17 \%$ ) & Fusiform & C. acutatum s.1. \\
\hline
\end{tabular}


each test concentration $(I)$ was also calculated as the difference between the radial growth of nonamended control $(C)$ and the radial growth of each test concentration $(T)$ as follows: $I(\%)=(1-T / C)$ $\times 100$. The $\mathrm{EC}_{50}$ values were calculated by linear regression of the probit-transformed relative inhibition on $\log 10$-transformed fungicide concentration using PROC PROBIT (SAS 9.2; SAS Institute, Cary, NC).

Statistical analysis. The average and standard deviation (SD) of the data were calculated using Microsoft Excel. The size of the conidia and appressoria and the diameter of the lesions are expressed as the average $\pm \mathrm{SD}$ in this paper. $\mathrm{EC}_{50}$ values were subjected to oneway ANOVA and compared by using the least significant difference test in SAS (SAS 9.2).

\section{Results}

Preliminary identification of the fungal isolates. A total of 125 fungal isolates were collected from diseased apple fruits. The isolates were then grouped into five groups based on the similarity of morphology (colony color and conidial size and shape). A subsample of 25 isolates (five from each group) were selected for further study. Based on the morphological characteristics and ITS sequence data, 14 of these isolates were identified as C. gloeosporioides s.l., and 11 were found to be $C$. acutatum s.l. (Table 3). For morphological and molecular analysis, five isolates of the $C$. gloeosporioides species complex and four isolates of the $C$. acutatum species complex were selected randomly for identification at species level.

Phylogenetic analysis. Five combined gene alignment data matrixes (ITS, TUB2, GAPDH, CAL, and CHS-1) for 37 sequences were used to identify the Colletotrichum species within $C$. gloeosporioides s.l. The combined matrixes of the aligned data consisted of 2,391 characters and gaps in the alignment. The identified isolates from the apples in the $C$. gloeosporioides complex are shown in Figure 1. The isolates in the C. gloeosporioides complex were clustered into three clades: one isolate clustered with $C$. gloeosporioides s.s., five (one from the present study and four from the KACC) with $C$. siamense, and three with $C$. fructicola. The $C$. siamense isolate was further confirmed via phylogenetic analysis using the gene sequences of ApMat.

To identify the Colletotrichum species within C. acutatum s.l., four gene alignment data matrixes (ITS, TUB2, GAPDH, and CHS-1) for 44 sequences were used. The combined matrixes of the aligned data consisted of 1,576 characters and gaps in the alignment. The isolates identified in the $C$. acutatum complex are presented in Figure 2. The apple isolates in $C$. acutatum s.l. could be identified with confidence as $C$. fioriniae and $C$. nymphaeae because the two isolates clustered together with $C$. fioriniae ex-type isolates CBS 23549 and CBS 125396, and five isolates (two from the present study and three collected from KACC) clustered with the $C$. nymphaeae ex-type isolate CBS 100065.

Morphological characteristics. The 7-day-old colony of $C$. gloeosporioides on PDA was white with aerial mycelium and edges (Fig. 3). The conidia were cylindrical, aseptate, hyaline, rounded at both ends, and 13.0 to $18.3 \times 4.8$ to $7.1 \mu \mathrm{m}$ (average $16.5 \pm 1.2 \times$ $6.2 \pm 0.6 \mu \mathrm{m})$. The appressoria were globose to cylindrical, brown, and 8.2 to $12.07 \times 5.9$ to $9.8 \mu \mathrm{m}$ (average $10.1 \pm 1.5 \times 8.0 \pm$ $1.1 \mu \mathrm{m}$ ), with an entire margin (Table 4). The growth rate of isolate ICKa85 on PDA was $10.3 \mathrm{~mm}$ per day. Mycelial growth was fastest on MA, followed by PDA, V8, OA, and CA.

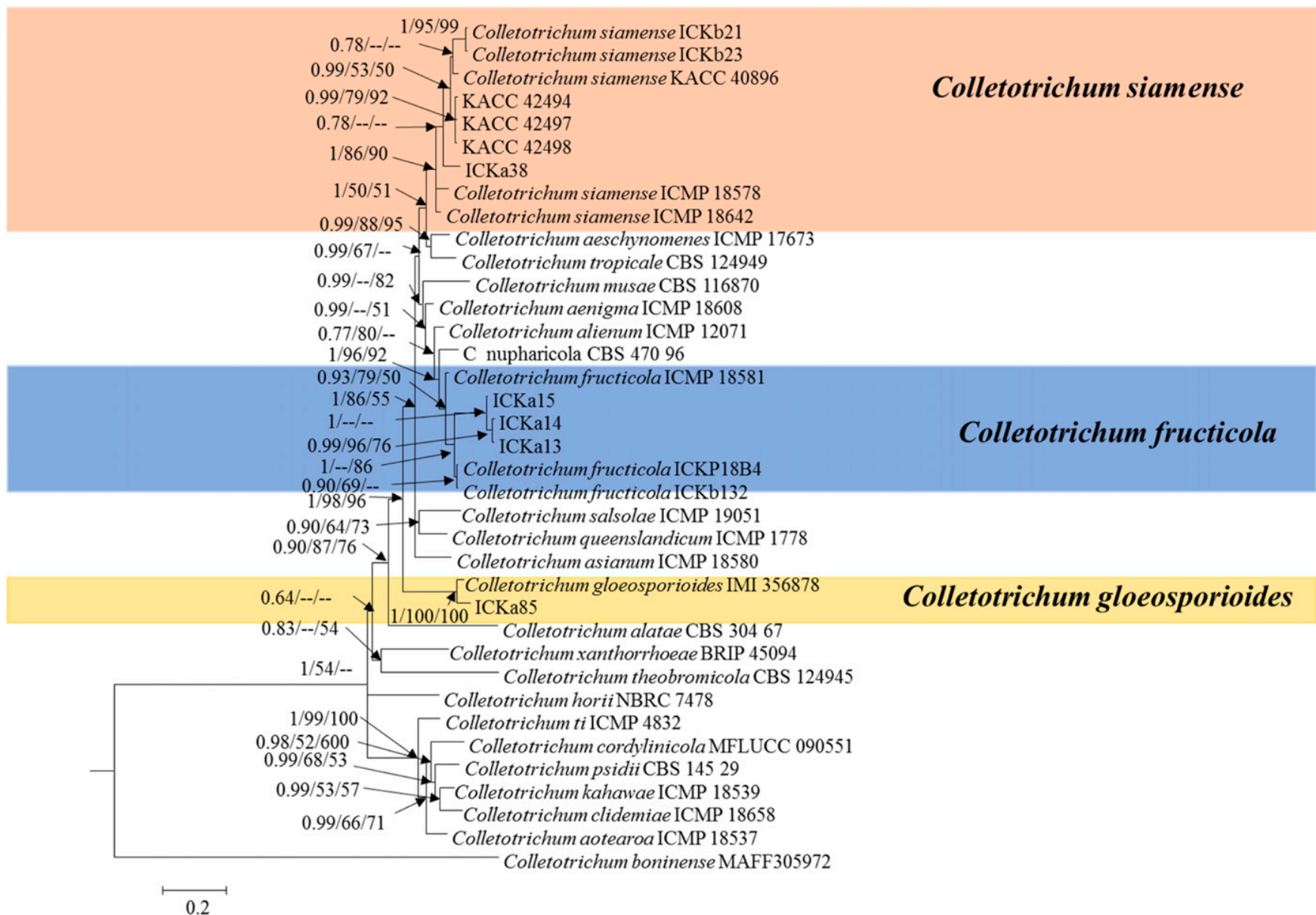

Fig. 1. Consensus tree based on the $50 \%$ majority rule obtained using Bayesian inference analysis of ITS, TUB2, GAPDH, CHS-1, and CAL sequence alignment. Bayesian posterior probability values $\geq 0.5$ and bootstrap support values $\geq 50 \%$ are presented at the nodes (posterior probability/maximum likelihood/maximum parsimony) Colletotrichum boninense was used as the outgroup. The sequences of reference Colletotrichum spp. within the C. gloeosporioides species complex were from Weir et al. (2012). The isolates obtained in this study are highlighted. 
The 7-day-old colony of $C$. siamense on PDA was olivaceous white with whitish aerial mycelium and edges (Fig. 3). The conidia were cylindrical, aseptate, hyaline, rounded at both ends, and 12.5 to $19.5 \times 4.9$ to $7.2 \mu \mathrm{m}$ (average $16.3 \pm 1.9 \times 6.5 \pm 0.9 \mu \mathrm{m}$ ). The appressoria were globose to cylindrical, entire or lobed, 7.4 to $12.0 \times$ 6.5 to $9.4 \mu \mathrm{m}$ (average $10.3 \pm 1.6 \times 8.2 \pm 0.9 \mu \mathrm{m}$ ), and brown (Table 4). The growth rate of isolate ICKa38 on PDA was $8.9 \mathrm{~mm}$ per day. Mycelial growth was fastest on MA followed by V8, PDA, OA, and CA.

The colony of $C$. fructicola after 7 days was light gray with whitish aerial mycelium and edges. The underside of the colony was gray with black zonation (Fig. 3). The conidia were cylindrical, aseptate, hyaline, rounded at both ends, and 14.6 to $24.4 \times 5.4$ to $7.5 \mu \mathrm{m}$ (average $18.1 \pm 2.2 \times 6.4 \pm 0.6 \mu \mathrm{m}$ ). The appressoria were ovoid, lobed, 8.6 to $17.8 \times 5.6$ to $14.33 \mu \mathrm{m}$ (average $12.3 \pm 2.16 \times 8.6 \pm 1.8 \mu \mathrm{m}$ ), and brown (Table 4 ). The growth rate of isolate ICKa15 on PDA was $12.10 \mathrm{~mm}$ per day, with mycelial growth fastest on PDA followed by $\mathrm{MA}, \mathrm{OA}, \mathrm{V} 8$, and CA.

After 7 days, the $C$. fioriniae colony on PDA was light gray with whitish aerial mycelium and edges. The underside of the colony was yellowish white with black zonation (Fig. 3). The conidia were fusiform to cylindrical, aseptate, hyaline, rounded at both ends, and 11.7 to $22.1 \times 4.5$ to $8.0 \mu \mathrm{m}$ (average $17.1 \pm 2.3 \times 5.8 \pm 0.8 \mu \mathrm{m}$ ); the appressoria were ovoid, lobed, 11.0 to $14.4 \times 7.3$ to $8.2 \mu \mathrm{m}$ (average $12.5 \pm 1.1 \times 7.7 \pm 0.6 \mu \mathrm{m}$ ), and brown (Table 4). The growth rate of isolate ICKS30 on PDA was $6.40 \mathrm{~mm}$ per day. Mycelial growth was fastest on V8 followed by OA, PDA, MA, and CA.

C. nymphaeae on PDA was gray with a white margin after 7 days of incubation in the dark at $25^{\circ} \mathrm{C}$ (Fig. 3). The conidia were smoothwalled, aseptate, straight, cylindrical to cylindric-clavate, with one end rounded and one end rounded to acute, and 11.1 to $18.0 \times 4.2$ to $6.8 \mu \mathrm{m}$ (average $13.8 \pm 1.4 \times 5.22 \pm 0.5 \mu \mathrm{m}$ ). The appressoria were medium, brown, ovoid with smooth margins, and 7.0 to $11.2 \times 5.7$ to $8.1 \mu \mathrm{m}$ (average $8.7 \pm 1.3 \times 7.0 \pm 0.8 \mu \mathrm{m}$; Table 4 ). The growth rate of isolate ICKS18 on PDA was $6.8 \mathrm{~mm}$ per day. Mycelial growth was fastest on OA followed by V8, PDA, MA, and CA.

The effect of temperature on mycelial growth of all isolates was almost similar. Active mycelium growth occurred at temperatures from 15 to $30^{\circ} \mathrm{C}$. Radial mycelial growth gradually increased from 15 to $25^{\circ} \mathrm{C}$ and then decreased, indicating that maximum mycelial growth rate for all isolates was at $25^{\circ} \mathrm{C}$.

Pathogenicity. Representative isolates of each Colletotrichum sp. were pathogenic on the detached apple fruits (Fig. 4). Inoculation with $C$. fructicola, $C$. siamense, $C$. nymphaeae, and $C$. fioriniae isolates led to the development of anthracnose symptoms on fruits using both the wounding and nonwounding approaches, whereas the $C$. gloeosporioides isolate was only capable of infecting wounded apples (Table 5). All of the Colletotrichum species exhibited higher virulence on the wounded apples compared with the nonwounded apples in terms of disease incidence and lesion size (Fig. 4;

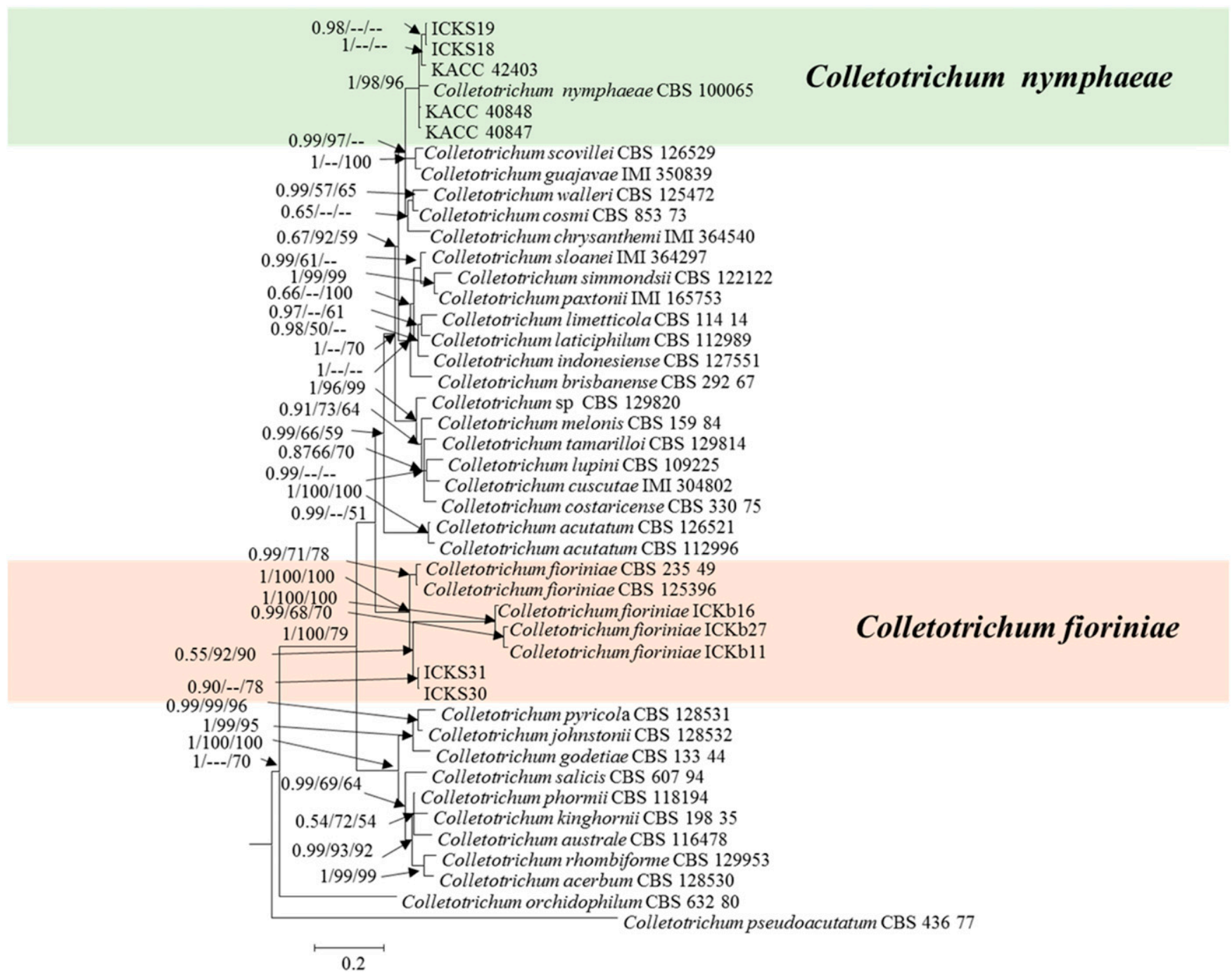

Fig. 2. Consensus tree based on the $50 \%$ majority rule obtained using Bayesian inference analysis of ITS, TUB2, GAPDH, and CHS-1 sequence alignment. Bayesian posterior probability values $\geq 0.5$ and bootstrap support values $\geq 50 \%$ are presented at the nodes (posterior probability/maximum likelihood/maximum parsimony). The sequences of the reference Colletotrichum spp. within the C. acutatum species complex were from Damm et al. (2012). The isolates obtained in this study are highlighted. 
Table 5). The fungal species were reisolated from the inoculated fruits and identified using the process described above to confirm Koch's postulates.

Sensitivity of Colletotrichum isolates to fungicides. Based on the $\mathrm{EC}_{50}$ values of fungicides against mycelial growth of different $\mathrm{Col}$ letotrichum species, tebuconazole was more effective compared with other fungicides used in this study (Table 6). Based on the $\mathrm{EC}_{50}$ values of different Colletotrichum species isolates, C. fructicola had significantly the highest $\mathrm{EC}_{50}$ values against all fungicides except tebuconazole. $\mathrm{EC}_{50}$ values $(204.6 \mu \mathrm{g} / \mathrm{ml})$ of mycelium growth of C. fructicola against thiophanate-methyl was higher than that of any other fungicide. The lowest $\mathrm{EC}_{50}$ of $C$. gloeosporioides and $C$. siamense was against carbendazim, with values of 0.03 and
$0.9 \mu \mathrm{g} / \mathrm{ml}$, respectively. The lowest $\mathrm{EC}_{50}$ of $C$. fioriniae was against tebuconazole and azoxystrobin, with values of 0.15 and $0.14 \mu \mathrm{g} / \mathrm{ml}$, respectively; The lowest $\mathrm{EC}_{50}$ of $C$. nymphaeae was against azoxystrobin with a value of $0.06 \mu \mathrm{g} / \mathrm{ml}$ (Table 6).

\section{Discussion}

Apple anthracnose is the most prevalent fruit disease in Gyeongbuk province in South Korea and the most challenging summer disease to control. Recently, many orchardists have reported that this disease could not be controlled even after employing the suggested spraying schedule. In this respect, a key finding of the present study is that different Colletotrichum spp. are responsible for apple anthracnose in Korea. Five phylogenetic species (C. gloeosporioides
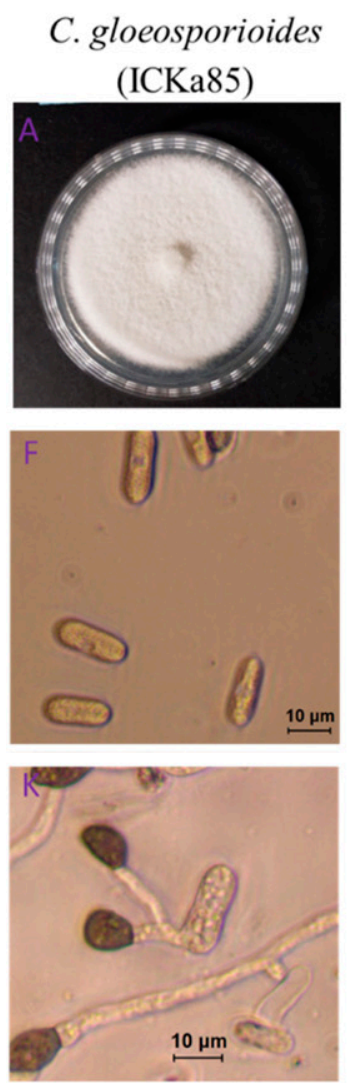

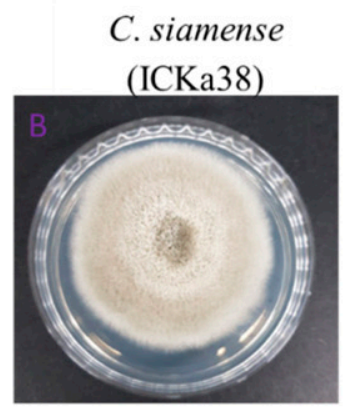

C. fructicola (ICKa15)
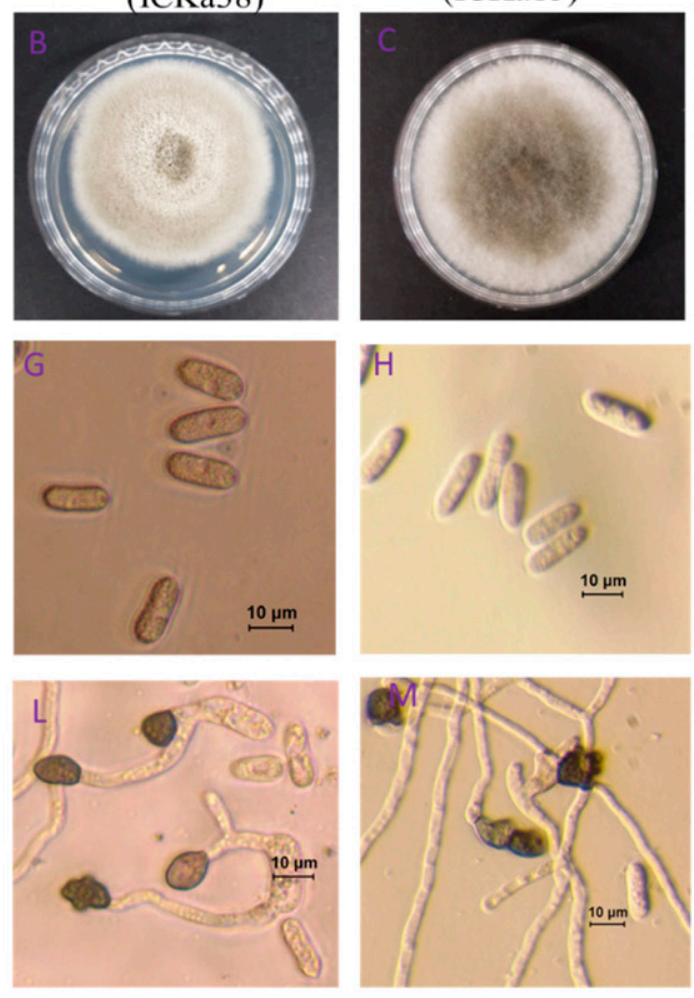
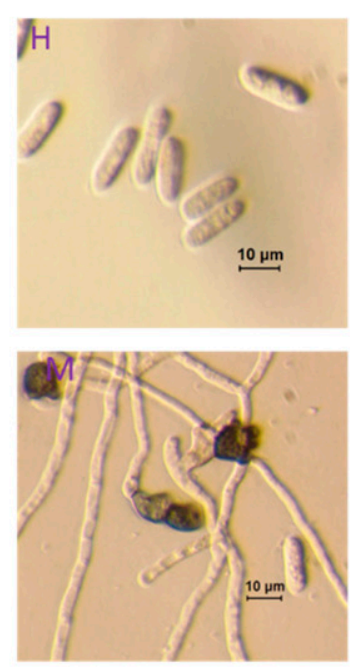

C. fioriniae

(ICKS30)
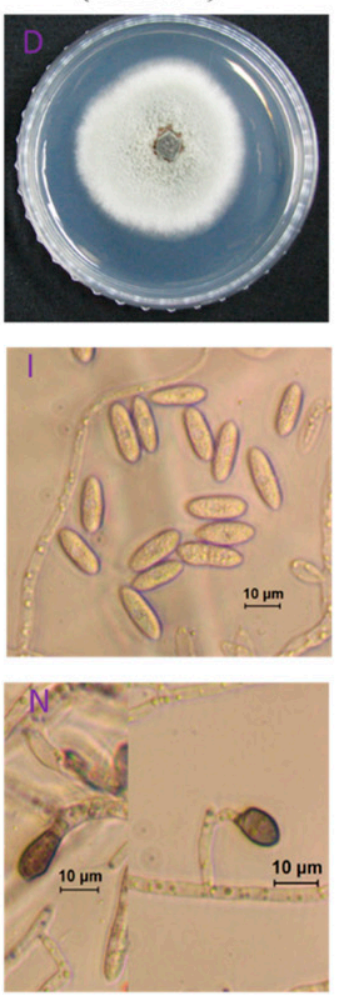

C. nymphaeae (ICKS18)
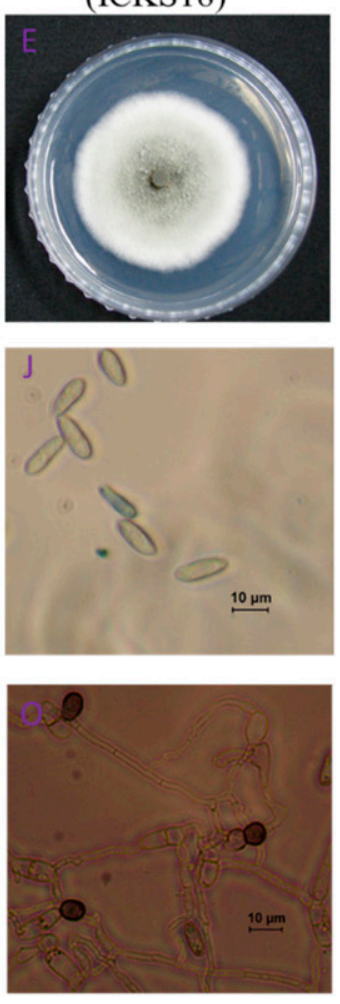

Fig. 3. Morphological characteristics of the Colletotrichum isolates characterized in the present study: A to E, 7-day-old colony on PDA; F to J, conidia; and K to 0 , appressoria.

Table 4. Morphological characterization of representative Colletotrichum sp. isolates identified in this study

\begin{tabular}{|c|c|c|c|c|c|}
\hline Characteristics & $\begin{array}{l}\text { C. gloeosporioides } \\
\text { (ICKa85) }\end{array}$ & C. siamense (ICKa38) & C. fructicola (ICKa15) & C. fioriniae (ICKS30) & C. nymphaeae (ICKS18) \\
\hline $\begin{array}{l}\text { Colonies, color } \\
\text { on PDA }\end{array}$ & $\begin{array}{l}\text { White with aerial mycelium } \\
\text { and edges }\end{array}$ & $\begin{array}{l}\text { Olivaceous white with } \\
\text { whitish aerial mycelium } \\
\text { and edges }\end{array}$ & $\begin{array}{l}\text { Light gray with whitish } \\
\text { aerial mycelium and } \\
\text { edges, gray with black } \\
\text { zonation in reverse }\end{array}$ & $\begin{array}{l}\text { Yellowish white with } \\
\text { black zonation }\end{array}$ & $\begin{array}{l}\text { Gray at center, white at the } \\
\text { margin, lack of aerial } \\
\text { mycelium, reverse } \\
\text { creamy white }\end{array}$ \\
\hline Conidia, shape & $\begin{array}{l}\text { Cylindrical, aseptate, } \\
\text { hyaline, rounded at both } \\
\text { ends }\end{array}$ & $\begin{array}{l}\text { Cylindrical, aseptate, } \\
\text { hyaline, rounded at both } \\
\text { ends }\end{array}$ & $\begin{array}{l}\text { Cylindrical, aseptate, } \\
\text { hyaline, rounded at both } \\
\text { ends }\end{array}$ & $\begin{array}{l}\text { Fusiform to cylindrical, } \\
\text { aseptate, hyaline, } \\
\text { rounded at both ends }\end{array}$ & $\begin{array}{l}\text { Smooth-walled, aseptate, } \\
\text { straight, cylindrical to } \\
\text { cylindric-clavate with } \\
\text { one end round and one } \\
\text { end rounded to acute }\end{array}$ \\
\hline Conidi & $\begin{array}{l}13.0 \text { to } 18.3 \times 4.8 \text { to } 7.1 \mu \mathrm{m} \\
(\text { avg. } 16.5 \pm 1.2 \times 6.2 \pm \\
0.6 \mu \mathrm{m})\end{array}$ & $\begin{array}{l}12.5 \text { to } 19.5 \times 4.9 \text { to } \\
7.2 \mu \mathrm{m}(\mathrm{avg} .16 .3 \pm \\
1.9 \times 6.5 \pm 0.9 \mu \mathrm{m})\end{array}$ & $\begin{array}{l}14.6 \text { to } 24.4 \times 5.4 \text { to } \\
7.5 \mu \mathrm{m}(\text { avg. } 18.1 \pm \\
2.2 \times 6.4 \pm 0.6 \mu \mathrm{m})\end{array}$ & $\begin{array}{l}11.7 \text { to } 22.1 \times 4.5 \text { to } \\
8.0 \mu \mathrm{m}(\operatorname{avg} .17 .1 \pm \\
2.3 \times 5.8 \pm 0.8 \mu \mathrm{m})\end{array}$ & $\begin{array}{l}11.1 \text { to } 18.0 \times 4.2 \text { to } \\
6.8 \mu \mathrm{m}(\operatorname{avg} .13 .8 \pm \\
1.4 \times 5.22 \pm 0.5 \mu \mathrm{m})\end{array}$ \\
\hline $\begin{array}{l}\text { Appressoria, } \\
\text { shape }\end{array}$ & $\begin{array}{l}\text { Globose to cylindrical, } \\
\text { entire margin }\end{array}$ & $\begin{array}{l}\text { Globose to cylindrical, } \\
\text { entire or lobed margin }\end{array}$ & Ovoid and lobed margin & $\begin{array}{l}\text { Medium brown ovoid with } \\
\text { lobed margin }\end{array}$ & $\begin{array}{l}\text { Medium brown ovoid with } \\
\text { smooth margin }\end{array}$ \\
\hline $\begin{array}{l}\text { Appressoria, } \\
\text { size }\end{array}$ & $\begin{array}{l}8.2 \text { to } 12.07 \times 5.9 \text { to } 9.8 \mu \mathrm{m} \\
(\text { avg. } 10.1 \pm 1.5 \times 8.0 \pm \\
1.1 \mu \mathrm{m})\end{array}$ & $\begin{array}{l}7.4 \text { to } 12.0 \times 6.5 \text { to } 9.4 \mu \mathrm{m} \\
(\text { avg. } 10.3 \pm 1.6 \times 8.2 \pm \\
0.9 \mu \mathrm{m})\end{array}$ & $\begin{array}{l}8.6 \text { to } 17.8 \times 5.6 \text { to } \\
14.33 \mu \mathrm{m}(\text { avg. } 12.3 \pm \\
2.16 \times 8.6 \pm 1.8 \mu \mathrm{m})\end{array}$ & $\begin{array}{l}11.0 \text { to } 14.4 \times 7.3 \text { to } \\
8.2 \mu \mathrm{m}(\mathrm{avg} .12 .5 \pm \\
1.1 \times 7.7 \pm 0.6 \mu \mathrm{m})\end{array}$ & $\begin{array}{l}7.0 \text { to } 11.2 \times 5.7 \text { to } 8.1 \mu \mathrm{m} \\
(\text { avg. } 8.7 \pm 1.3 \times 7.0 \pm \\
0.8 \mu \mathrm{m})\end{array}$ \\
\hline
\end{tabular}


s.s., C. fructicola, C. siamense, C. nymphaeae, and C. fioriniae) belonging to the $C$. gloeosporioides and $C$. acutatum species complexes were identified in diseased apples using multigene phylogenetic and morphological analyses. This diverse range of causal agents may be a significant reason why numerous difficulties have been experienced in managing this disease.
A recent study based on a phylogenic approach using ITS and GAPDH showed that $C$. fructicola, $C$. siamense, $C$. nymphaeae, and $C$. fioriniae were associated with apple anthracnose in South Korea (Oo et al. 2018). Along with four Colletotrichum species reported by Oo et al. (2018), this study identified $C$. gloeosporioides s.s. as a causal agent of apple anthracnose in South Korea.
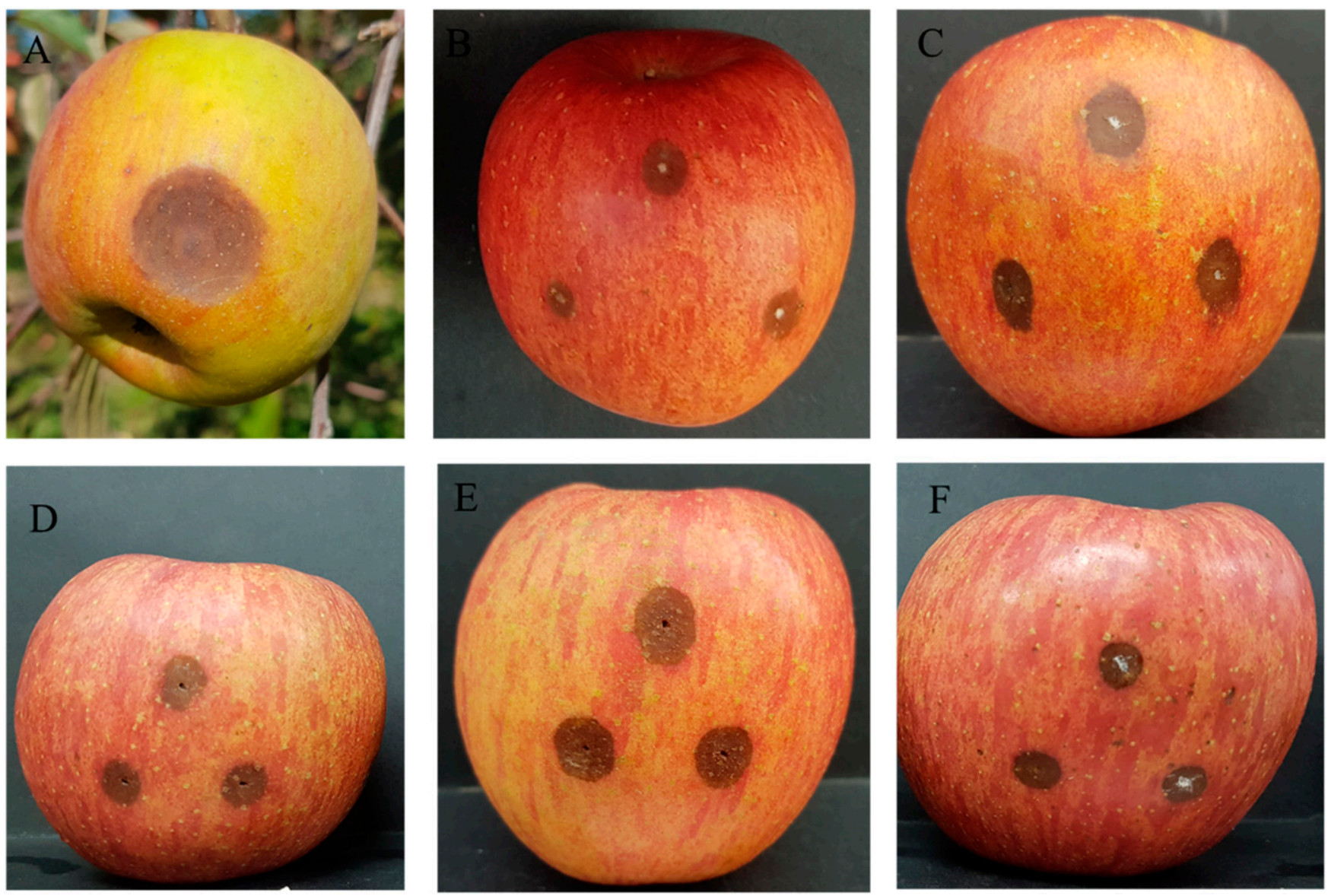

Fig. 4. Anthracnose symptoms on naturally and artificially inoculated apples. A, Symptomatic fruit from an apple orchard. B, Colletotrichum gloeosporioides (ICKa85). C, C. siamense (ICKa38). D, C. fructicola (ICKa15). E, C. fioriniae (ICKS30). F, C. nymphaeae (ICKS18).

Table 5. Disease incidence and lesion diameter produced by different Colletotrichum isolates on apples ${ }^{\mathrm{z}}$

\begin{tabular}{|c|c|c|c|c|}
\hline \multirow[b]{2}{*}{ Species and isolate } & \multicolumn{2}{|c|}{ Wounding method } & \multicolumn{2}{|c|}{ Lesion diameter (nonwounding method) } \\
\hline & Disease incidence $(\%)$ & Lesion diameter $(\mathrm{cm})$ & Disease incidence $(\%)$ & Lesion diameter $(\mathbf{c m})$ \\
\hline C. gloeosporioides (ICKa85) & 100 & $8.5 \pm 1.25$ & 0 & - \\
\hline C. siamense (ICKa38) & 100 & $17.2 \pm 1.83$ & 10 & $5.2 \pm 1.3$ \\
\hline C. fructicola (ICKa15) & 100 & $11.03 \pm 45$ & 13.3 & $4.5 \pm 0.7$ \\
\hline C. fioriniae (ICKS30) & 100 & $14.52 \pm 1.91$ & 10 & $4.2 \pm 0.1 .2$ \\
\hline C. nymphaeae (ICKS18) & 100 & $9.34 \pm 1.2$ & 10 & $4.0 \pm 0.5$ \\
\hline
\end{tabular}

${ }^{\mathrm{z}}$ Lesion diameter presented as the mean \pm standard deviation.

Table 6. Mean half maximum effective concentration $\left(\mathrm{EC}_{50}\right)$ value of mycelial growth of Colletotrichum spp. to four fungicides ${ }^{\mathrm{z}}$

\begin{tabular}{lcccc}
\hline & \multicolumn{3}{c}{ EC $_{\mathbf{5 0}} \mathbf{( \mu \mathbf { g } / \mathbf { m l } )}$} \\
\cline { 2 - 6 } Colletotrichum spp. & Carbendazim & Thiophanate-methyl & Tebuconazole & Azoxystrobin \\
\hline C. fructicola & $150 \pm 8.1 \mathrm{a}$ & $204.6 \pm 10.2 \mathrm{a}$ & $0.8 \pm 0.2 \mathrm{c}$ & \\
C. nymphaeae & $11.4 \pm 1.3 \mathrm{~b}$ & $14.02 \pm 2.5 \mathrm{~b}$ & $0.12 \pm 0.02 \mathrm{~d}$ & $0.06 \pm 0.3 \mathrm{a}$ \\
C. fioriniae & $1.4 \pm 0.2 \mathrm{c}$ & $5.9 \pm 1.0 \mathrm{c}$ & $0.15 \pm 0.06 \mathrm{~d}$ & $0.14 \pm 0.02 \mathrm{~d}$ \\
C. siamense & $0.9 \pm 0.2 \mathrm{~d}$ & $1.38 \pm 0.5 \mathrm{~d}$ & $2.1 \pm 0.4 \mathrm{a}$ & $11.6 \pm 1.7 \mathrm{c}$ \\
C. gloeosporioides & $0.03 \pm 0.01 \mathrm{e}$ & $0.51 \pm 0.1 \mathrm{e}$ & $1.45 \pm 0.1 \mathrm{~b}$ & \\
\hline
\end{tabular}

${ }^{\mathrm{z}} \mathrm{EC}_{50}$ values followed by different letters are significantly different among the species within each fungicide based on LSD test with $P=0.01$. 
C. gloeosporioides s.s. is a very common causal agent of Citrus anthracnose worldwide (Weir et al. 2012) and has been found in a number of other hosts, including Broussonetia papyrifera, Ficus, Mangifera, Pueraria, and Vitis (Weir et al. 2012; Yan et al. 2011). In Korea, it has been reported to be a causal agent of apple anthracnose (KSPP 2009). C. gloeosporioides s.s. has also been isolated from Ficus carica, Liriodendron chinense, Prunus avium, Prunus salicina, and Diospyros kaki in South Korea (Cheon et al. 2012; Choi et al. 2012, 2013; Hassan et al. 2019a; KSPP 2009; Lee and Kwak 2014). C. gloeosporioides s.s. is also often associated with the teleomorphic Glomerella cingulata (Weir et al. 2012). C. siamense is a biologically and geographically diverse species that has been recorded as a pathogen in multiple hosts (Cai et al. 2009; Weir et al. 2012). It was isolated and described by Prihastuti et al. (2009) as a causal agent for coffee berry disease. The present study identified $C$. siamense as a causal agent of apple anthracnose after it was previously reported to cause anthracnose in $\mathrm{D}$. kaki and $P$. salicina in South Korea (Hassan et al. 2018, 2019a). Along with C. siamense, C. fructicola was also isolated and described by Prihastuti et al. (2009) for the first time as a causal agent for coffee berry anthracnose. This is a common pathogen, with a wide range of hosts, including mangos, grapes, pears, and cassava (Bragança et al. 2016; Jiang et al. 2014; Lima et al. 2013; Peng et al. 2013; Weir et al. 2012), possibly due to its parasitic and endophytic lifestyle. In our previous article, $C$. fructicola was identified as a causal agent of apple anthracnose (Kim et al. 2018), and it has also been isolated as a leaf endophyte in several plants (Lima et al. 2013; Weir et al. 2012). C. gloeosporioides s.s., C. siamense, and C. fructicola belong to the Musae clade of the $C$. gloeosporioides complex described by Weir et al. (2012). The morphological characteristics of these Colletotrichum species are almost identical; thus, separating them on the basis of their morphological features was very difficult. For example, cylindrical and round-ended conidia were common to all three species. The morphological characteristics of these isolates also overlapped with other taxa within $C$. gloeosporioides s.l., with the colony appearance, conidial measurements, and growth rates of the Colletotrichum spp. within the $C$. gloeosporioides complex almost identical to or within the range of the type specimens (De Silva et al. 2017; Weir et al. 2012). Given this high degree of morphological similarity, multigene phylogenetic analysis can be used to disentangle Colletotrichum spp. (Cai et al. 2009; Weir et al. 2012). Phylogenetic analysis using ITS, TUB2, GAPDH, CAL, and CHS-1 sequences clearly separated the three species, which were located within a distinct phylogenetic clade in C. gloeosporioides s.l., with a high posterior probability (Fig. 1). The $C$. siamense isolates were further verified via phylogenetic analysis using ApMat sequence data, with ApMat possibly a strongly informative gene for the identification of $C$. siamense (Silva et al. 2012; Weir et al. 2012).

The isolates that we identified as $C$. fioriniae and $C$. nymphaeae belong to the $C$. acutatum species complex. $C$. fioriniae has been reported to be endophytic in some cases and entomopathogenic in others. It has also been reported as a causal agent of anthracnose in a wide range of crops and wild plants worldwide, including apple (Baroncelli et al. 2014; Damm et al. 2012; Faedda et al. 2011; Guarnaccia et al. 2019; Lubbe et al. 2004). In Korea, C. fioriniae has been isolated as a pathogen from different crops including Lycium chinense, $P$. salicina, Prunus persica, and Solanum melongena (Hassan et al. 2019a; Lee at al. 2018; Oo and Oh 2017; Xu et al. 2018). To the best of our knowledge, the present study is the second to report apple anthracnose caused by $C$. fioriniae in Korea. C. nymphaeae is a very common anthracnose pathogen in strawberry crops within $C$. acutatum s.l. (Damm et al. 2012; Jayawardena et al. 2016). It has been isolated as a causal agent of strawberry anthracnose in Bulgaria, Canada, China, France, Israel, Italy, Kenya, Netherlands, South Africa, Spain, Switzerland, the United Kingdom, and the United States (Damm et al. 2012; Jayawardena et al. 2016). $C$. nymphaeae is also associated with anthracnose in many other hosts, such as Eriobotrya japonica, Nuphar luteum, and M. domestica (Damm et al. 2012; Velho et al. 2014; Wu et al. 2018). Very recently, it has been isolated from Japanese plum and persimmon in Korea
(Hassan et al. 2019a, 2019b). To the best of our knowledge, the present study represents the second time $C$. nymphaeae has been identified as a causative agent of apple anthracnose.

The $C$. fioriniae isolates were easily differentiated from those of $C$. nymphaeae based on their fusiform conidia (Fig. 3). Molecular analysis using ITS, TUB2, GAPDH, and CHS-1 sequence data also clearly separated these two species. The colony color and conidial shape of $C$. nymphaeae were not identical with $C$. gloeosporioides s.l. isolates (Fig. 3), although it is known that the separation of $C$. nymphaeae from $C$. gloeosporioides based on morphological characteristics is very difficult (Johnson et al. 1997). However, multigene sequence analysis, especially that using TUB2, is unequivocal in distinguishing C. nymphaeae from other species (Damm et al. 2012).

Pathogenicity assays were employed in the present study to determine the aggressiveness of the different species identified within $C$. gloeosporioides s.l. and C. acutatum s.l. Aggressiveness was estimated based on lesion size and disease incidence. In terms of disease incidence, all the isolates exhibited comparable aggressiveness except $C$. gloeosporioides s.s., which did not infect unwounded apples. All the isolates showed variable aggressiveness in terms of disease incidence (Table 5).

Another important outcome of this study was the reassessment of six isolates collected from the KACC in South Korea. Three isolates (KACC42494, KACC42497, and KACC42498) deposited in the $\mathrm{KACC}$ as $C$. gloeosporioides s.s. were identified as $C$. siamense in the present study, and the isolates KACC40847, KACC40848, and KACC42403, deposited in the KACC as $C$. acutatum s.s., were identified as $C$. nymphaeae. This illustrates the importance of verifying the Colletotrichum strains deposited in the KACC.

Many apple growers in South Korea rely on application of fungicides with different modes of action. This study determines the selectivity of different Colletotrichum species to fungicides (thiophanatemethyl, tebuconazole, azoxystrobin, and carbendazim) having different modes of action. $\mathrm{EC}_{50}$ values estimated in this study for Colletotrichum species against tebuconazole were comparatively low, suggesting this fungicide may provide good control efficacy in field conditions. To choose effective fungicides, more field study is required in the future. $C$. fructicola showed more tolerance to fungicides (except tebuconazole) compared with other Colletotrichum species. The $\mathrm{EC}_{50}$ value of specific Colletotrichum species varied greatly among the fungicides, which deserves to be further investigated to improve the efficacy of the management strategies of apple bitter rot. In conclusion, the present study provides a better insight into the diversity of Colletotrichum species in the incidence of apple anthracnose in commercial Korean apple orchards in Gyeongbuk province. C. gloeosporioides s.s., C. fructicola, $C$. siamense, $C$. nymphaeae, and $C$. fioriniae were identified as causal agents of apple anthracnose based on colony and conidial morphological characteristics, molecular features, and pathogenicity testing. It also provides useful information for the effective control of apple anthracnose in South Korea.

\section{Acknowledgments}

We thank all our lab mates for their help during study periods.

\section{Literature Cited}

Baroncelli, R., Sreenivasaprasad, S., Sukno, S. A., Thon, M. R., and Holub, E. 2014. Draft genome sequence of Colletotrichum acutatum sensu lato (Colletotrichum fioriniae). Genome Announc. 2:e00112-14.

Baroncelli, R., Talhinhas, P., Pensec, F., Sukno, S. A., Le Floch, G., and Thon, M. R. 2017. The Colletotrichum acutatum species complex as a model system to study evolution and host specialization in plant pathogens. Front. Microbiol. 8:2001.

Basannagari, B., and Kala, C. P. 2013. Climate change and apple farming in Indian Himalayas: A study of local perceptions and responses. PLoS One 8:e77976.

Bragança, C. A. D., Silva, L. L., Haddad, F., and Oliveira, S. A. S. 2016. First report of Colletotrichum fructicola causing anthracnose in cassava (Manihot esculenta) in Brazil. Plant Dis. 100:857.

Cai, L., Hyde, K. D., Taylor, P. W. J., Weir, B. S., Waller, J., Abang, M. M., Zhang, J. Z., Yang, Y. L., Phoulivong, S., Liu, Z. Y., Prihastuti, H., Shivas, R. G., McKenzie, E. H. C., and Johnston, P. R. 2009. A polyphasic approach for studying Colletotrichum. Fungal Divers. 39:183-204. 
Carbone, I., and Kohn, L. M. 1999. A method for designing primer sets for speciation studies in filamentous ascomycetes. Mycologia 91:553-556.

Chen, S. N., Luo, C. X., Hu, M. J., and Schnabel, G. 2016. Sensitivity of Colletotrichum species, including $C$. fioriniae and $C$. nymphaeae, from peach to demethylation inhibitor fungicides. Plant Dis. 100:2434-2441.

Cheon, W., and Jeon, Y. 2015. Survey of major diseases occurred on apple in northern Gyeongbuk from 2013 to 2014. Res. Plant Dis. 21:261-267.

Cheon, W., Kim, Y. S., and Jeon, Y. H. 2012. First report of anthracnose caused by Colletotrichum gloeosporioides on Malus prunifolia in Korea. Plant Dis. 96:766.

Choi, I. Y., Park, J. H., Cho, S. E., and Shin, H. D. 2013. First confirmed report of anthracnose fruit rot caused by Colletotrichum gloeosporioides on common fig in Korea. Plant Dis. 97:1119.

Choi, O., Choi, O., Kwak, Y.-S., Kim, J., and Kwon, J.-H. 2012. Spot anthracnose disease caused by Colletotrichum gloeosporioides on tulip tree in Korea. Mycobiology 40:82-84.

Choi, S., and Hinkle, A. F. 2017. South Korea: 2017 Apple Report - Revised. GAIN report no. KS1733. https://www.fas.usda.gov/data/south-korea-2017apple-report-revised

Damm, U., Cannon, P. F., Woudenberg, J. H. C., and Crous, P. W. 2012. The Colletotrichum acutatum species complex. Stud. Mycol. 73:37-113.

De Silva, D. D., Ades, P. K., Crous, P. W., and Taylor, P. W. J. 2017. Colletotrichum species associated with chili anthracnose in Australia. Plant Pathol. 66:254-267.

Faedda, R., Agosteo, G. E., Schena, L., Mosca, S., Frisullo, S., Magnano di San Lio, G., and Cacciola, S. O. 2011. Colletotrichum clavatum sp. nov. identified as the causal agent of olive anthracnose in Italy. Phytopathol. Mediterr. 50:283-302.

Fu, M., Crous, P. W., Bai, Q., Zhang, P. F., Xiang, J., Guo, Y. S., Zhao, F. F., Yang, M. M., Hong, N., Xu, W. X., and Wang, G. P. 2019. Colletotrichum species associated with anthracnose of Pyrus spp. in China. Persoonia 42:1-35.

Glass, N. L., and Donaldson, G. C. 1995. Development of primer sets designed for use with the PCR to amplify conserved genes from filamentous ascomycetes. Appl. Environ. Microbiol. 61:1323-1330.

Guarnaccia, V., Gilardi, G., Martino, I., Garibaldi, A., and Gullino, M. L. 2019. Species diversity in Colletotrichum causing anthracnose of aromatic and ornamental Lamiaceae in Italy. Agronomy (Basel) 9:613.

Hassan, O., Jeon, J. Y., Chang, T., Shin, J. S., and Oh, N. K. 2018. Molecular and morphological characterization of Colletotrichum species in the Colletotrichum gloeosporioides complex associated with persimmon anthracnose in South Korea. Plant Dis. 102:1015-1024.

Hassan, O., Lee, D. W., and Chang, T. 2019b. First report of anthracnose of persimmon caused by Colletotrichum nymphaeae in Korea. Plant Dis. 103:1772.

Hassan, O., Lee, Y. S., and Chang, T. 2019a. Colletotrichum species associated with Japanese plum (Prunus salicina) anthracnose in South Korea. Sci. Rep. 9:12089.

Jayawardena, R. S., Huang, J. K., Jin, B. C., Yan, J. Y., Li, X. H., Hyde, K. D., Bahkali, A. H., Yin, S. L., and Zhang, G. Z. 2016. An account of Colletotrichum species associated with strawberry anthracnose in China based on morphology and molecular data. Mycosphere 7:1147-1163.

Jiang, J., Zhai, H., Li, H., Wang, Z., Chen, Y., Hong, N., Wang, G., Chofong, G. N., and $\mathrm{Xu}, \mathrm{W}$. 2014. Identification and characterization of Colletotrichum fructicola causing black spots on young fruits related to bitter rot of pear (Pyrus bretschneideri Rehd.) in China. Crop Prot. 58:41-48.

Johnson, D. A., Carris, L. M., and Rogers, J. D. 1997. Morphological and molecular characterization of Colletotrichum nymphaeae and C. nupharicola sp. nov. on water-lilies (Nymphaea and Nuphar). Mycol. Res. 101:641-649.

Kim, C., Hassan, O., Lee, D., and Chang, T. 2018. First report of anthracnose of apple caused by Colletotrichum fructicola in Korea. Plant Dis. 102:2653.

Korea Rural Economic Institute (KREI). 2018. https://www.krei.re.kr/eng/ index.do.

Korean Society of Plant Pathology (KSPP). 2009. List of Plant Diseases in Korea, 5th Ed. Korean Society of Plant Pathology, Seoul, South Korea.

Lee, D., Hassan, O., Kim, C., and Chang, T. 2018. First report of peach (Prunus persica) anthracnose caused by Colletotrichum fioriniae in Korea. Plant Dis. 102:2650.

Lee, J. H., and Kwak, Y.-S. 2014. First report of anthracnose of Ledebouriella seseloides caused by Colletotrichum gloeosporioides in Korea. J. Phytopathol. $162: 342-344$.
Lee, S.-Y., Park, S.-J., Lee, J.-J., Back, C.-G., Ten, L. N., Kang, I.-K., and Jung, H.-Y. 2017. First report of fruit rot caused by Fusarium decemcellulare in apples in Korea. Kor. J. Mycol. 45:54-62.

Lima, N. B., de A. Batista, M. V., De Morais, M. A., Jr., Barbosa, M. A. G., Michereff, S. J., Hyde, K. D., and Câmara, M. P. S. 2013. Five Colletotrichum species are responsible for mango anthracnose in northeastern Brazil. Fungal Divers. 61:75.

Liu, X., Li, B., Cai, J., Zheng, X., Feng, Y., and Huang, G. 2018. Colletotrichum species causing anthracnose of rubber trees in China. Sci. Rep. 8:10435.

Lubbe, C. M., Denman, S., Cannon, P. F., Groenewald, J. Z., Lamprecht, S. C., and Crous, P. W. 2004. Characterization of Colletotrichum species associated with diseases of Proteaceae. Mycologia 96:1268-1279.

Maddison, W. P., and Maddison, D. R. 2011. Mesquite: A modular system for evolutionary analysis. Version 2.75. http://www.mesquiteproject.org/.

Munir, M., Amsden, B., Dixon, E., Vaillancourt, L., and Gauithier, N. A. W. 2016 Characterization of Colletotrichum species causing bitter rot of apple in Kentucky orchards. Plant Dis. 100:2194-2203.

Oo, M. M., and Oh, S.-K. 2017. Identification and characterization of new record of grape ripe rot disease caused by Colletotrichum viniferum in Korea. Mycobiol. 45:421-425.

Oo, M. M., Yoon, H. Y., Jang, H. A., and Oh, S. K. 2018. Identification and characterization of Colletotrichum species associated with bitter rot disease of apple in South Korea. Plant Pathol. J. 34:480-489.

Park, M. S., Kim, B.-R., Park, I.-H., and Hahm, S.-S. 2018. First report of two Colletotrichum species associated with bitter rot on apple fruit in Korea $-C$. fructicola and C. siamense. Mycobiology 46:154-158.

Peng, L.-J., Sun, T., Yang, Y.-L., Cai, L., Hyde, K. D., Bahkali, A. H., and Liu, Z.-Y. 2013. Colletotrichum species on grape in Guizhou and Yunnan provinces, China. Mycoscience 54:29-41.

Prihastuti, H., Cai, L., Chen, H., McKenzie, E., and Hyde, K. 2009. Characterization of Colletotrichum species associated with coffee berries in northern Thailand. Fungal Divers. 39:89.

Rambaut, A., and Drummond, A. 2009. FigTree v1. 3.1: Tree figure drawing tool. Institute of Evolutionary Biology, Edinburgh, U.K. http://tree.bio.ed.ac.uk/ software/figtree/.

Ronquist, F., Teslenko, M., van der Mark, P., Ayres, D. L., Darling, A., Höhna, S. Larget, B., Liu, L., Suchard, M. A., and Huelsenbeck, J. P. 2012. MrBayes 3.2: Efficient Bayesian phylogenetic inference and model choice across a large model space. Syst. Biol. 61:539-542.

Silva, D. N., Talhinas, P., Várzea, V., Cai, L., Paulo, O. S., and Batista, D. 2012 Application of the Apn2/MAT locus to improve the systematics of the Colletotrichum gloeosporioides complex: An example from coffee (Coffea spp.) hosts. Mycologia 104:396-409.

Tamura, K., Stecher, G., Peterson, D., Filipski, A., and Kumar, S. 2013. MEGA6 Molecular Evolutionary Genetics Analysis version 6.0. Mol. Biol. Evol. 30: 2725-2729.

Templeton, M. D., Rikkerink, E. H. A., Solon, S. L., and Crowhurst, R. N. 1992. Cloning and molecular characterization of the glyceraldehyde-3-phosphate dehydrogenase-encoding gene and cDNA from the plant pathogenic fungus Glomerella cingulata. Gene 122:225-230.

Velho, A. C., Stadnik, M. J., Casanova, L., Mondino, P., and Alaniz, S. 2014. First report of Colletotrichum nymphaeae causing apple bitter rot in southern Brazil. Plant Dis. 98:567.

Weir, B. S., Johnston, P. R., and Damm, U. 2012. The Colletotrichum gloeosporioides species complex. Stud. Mycol. 73:115-180.

White, T. J., Bruns, T., Lee, S., and Taylor, J. W. 1990. Amplification and direct sequencing of fungal ribosomal RNA genes for phylogenetics. Pages 315-322 in: PCR Protocols: A Guide to Methods and Applications. M. A. Innis, D. H. Gelfand, J. J. Sninsky, and T. J. White, eds. Academic Press, New York, NY.

Wu, W. X., Liu, L., Huang, X. Q., and Zhang, L. 2018. First report of anthracnose caused by Colletotrichum nymphaeae on loquat fruit in China. Plant Dis. 102 243

Xu, S. J., Aktaruzzaman, M., Kim, B. S., Kim, J. Y., and Shin, H. D. 2018. First report of anthracnose caused by Colletotrichum fioriniae on eggplant fruits in Korea. Plant Dis. 102:2642.

Yan, J., Wu, P. S., Du, H. Z., and Zhang, Q. E. 2011. First report of black spot caused by Colletotrichum gloeosporioides on paper mulberry in China. Plant Dis. 95:880. 